\title{
LAS REPERCUSIONES DE LA CRISIS TRIGUERA DE 1629-1631 SOBRE LAS FINANZAS DE LA CIUDAD DE VALENCIA*
}

\author{
Amparo FELIPO ORTS
}

Universitat de València

\begin{abstract}
Resumen
La incidencia de la crisis triguera de 1629-1631 obligó a la ciudad de Valencia a desarrollar diversos sistemas de avituallamiento. Pero ello no pudo impedir que se produjera un excepcional aumento de los precios del cereal, frente al cual el Municipio desarrolló una arriesgada política que abocó en la falta de numerario de la Taula de Canvis. La búsqueda de soluciones ante el déficit se tradujo en la elaboración, desde diferentes instancias políticas, de numerosos memoriales proponiendo múltiples y variados arbitrios frente a la crisis, cuyo análisis constituye el objetivo primordial de este artículo.

Palabras clave: Valencia, siglo XVII, carestía, trigo, déficit, crisis, finanzas, memoriales, arbitrios.
\end{abstract}

\section{Summary}

The effect of the wheat crisis of 1629-1631 forced the city of Valencia to develop various means of provisioning. But it was unable to prevent a phenomenal increase in cereal prices, in the face of which the Town Council devised a risky policy which culminated in the Taula de Canvis's lack of funds. Faced with this deficit, the search for solutions resulted in different political authorities drawing up numerous reports proposing a great variety of measures against the crisis, the analysis of which is the prime objective of this article.

Key words: Valencia, seventeenth century, shortage, wheat, deficit, crisis, finances, reports, measures

\footnotetext{
* Este trabajo se inscribe en el proyecto de investigación «Elites de poder y relaciones sociales en la Valencia Moderna (BHA2002-01075), subvencionado por el Ministerio de Ciencia y Tecnología.
} 
Es sabido que la ciudad de Valencia fue tradicionalmente deficitaria en trigo, teniendo que depender de la adquisición de cereal procedente del exterior. Ello determinó que, con el fin de impedir que su comercio quedara sometido a la atracción de la oferta y la demanda, el control de su abastecimiento fuera asumido por el Consejo de la Ciudad, que recurrió a tal fin a diferentes métodos. Así, mientras en el siglo XV el avituallamiento estuvo mayoritariamente en manos de particulares, limitándose la función de los jurados a fomentar y regular esta actividad mediante procedimientos tales como la concesión de préstamos sin interés, el aseguramiento de los precios de venta y la concesión de ayudas a la importación, durante la centuria siguiente se impuso la compra directa por parte de la Ciudad por medio de síndicos, de los cuales el más importante era el destacado en Sicilia, que desde 1547 adquirió carácter permanente. No obstante, tampoco este método estuvo exento de problemas, derivados de los gastos originados por los intereses de la moneda, el aseguramiento con los fletes, el salario del síndico de Sicilia y el de su corresponsal, la venta de trigo a un precio más bajo que el de compra... cúmulo de gastos que provocó ya en torno a 1612 un déficit superior a 300.000 libras. Ello demostró que, junto a grandes ventajas, este sistema presentaba también serios inconvenientes y que su gestión no siempre era eficaz, lo que unido a otros motivos económicos determinó al monarca a revocar la autorización anteriormente concedida a la Ciudad de mantener un síndico permanente en Palermo. Con su supresión se introdujo una nueva modalidad de administración según la cual el Municipio cedía la adquisición de granos a determinados mercaderes a cambio de una comisión, reservándose además su control. Este sistema funcionó satisfactoriamente en principio ya que la ciudad no sólo estuvo bien abastecida sino que incluso en repetidas ocasiones se vio en la necesidad de repartir parte del trigo almacenado entre los pueblos vecinos para evitar que se pudriera, al tiempo que los precios lograron mantener su estabilidad.

Sin embargo, todas las previsiones se mostraban insuficientes ante la carestía general que afectó a Europa entre 1629 y 1631 de la que tampoco Valencia pudo escapar. Los efectos de la misma comenzaron a sentirse a raiz de las malas cosechas de 1628 , a las que sucedieron otras de igual signo en 1629 y 1630 , viéndose truncadas las esperanzas puestas en las, previsiblemente mejores, de 1631 por las inundaciones del mes de junio. Sólo a partir de 1632 comenzó a invertirse la tendencia por lo que el Consell decidió bajar el precio del cahíz y aumentar el peso de la hogaza de pan. No obstante, para Valencia, tanto o más peligrosa que la propia carestía interna, fueron las dificultades de aprovisionamiento desde el exterior motivadas no sólo por la misma carencia general, sino por la ruptura comercial con Inglaterra y Holanda a consecuencia de la guerra y por la prohibición de comercio con Cataluña, Francia e ltalia, como medida preventiva contra la peste que las asolaba.

En esta coyuntura, para luchar contra la falta de trigo la Ciudad tuvo que vencer enormes dificultades y paralelamente desarrollar una política dispendiosa cuyo final fue el de acabar empeñada. En principio, habiéndose mostrado totalmente insuficiente el sistema habitual, tuvieron que ponerse a contribución todos los recursos secularmente explotados tales como el sistema de seguretats -por el cual la Ciudad concluía 
acuerdos, habitualmente combinados con la concesión de préstamos, con negociantes que se comprometían a importar determinadas cantidades de trigo, especificando el plazo de tiempo previsto, la procedencia del cereal y el precio de venta- y la atracción de abastecedores mediante la promesa de concesión de ayudas de costa. Pero si en otras ocasiones estas ayudas habían propiciado la llegada a Valencia de barcos procedentes de Gran Bretaña, Italia o Francia, entre otros países ${ }^{1}$, en este caso los resultados conseguidos fueron muy mediocres ${ }^{2}$ por cuanto tres factores principales dificultaron el tráfico normal de granos. En primer lugar, como es sabido, también la escasez era grande en otras zonas y la prima, pese a ser más elevada que otras veces, se mostró insuficiente para atraer navíos al Grao. También contribuyó a restar afluencia al puerto la peste que afectó a diversos países entre 1628 y 1631 porque, como era costumbre, en cuanto llegaron las noticias de la epidemia se estableció, como sistema preventivo, un cordón sanitario que impidió la entrada de quienes procedieran de los lugares infectados, de lo que constituye una prueba fehaciente la larga serie de pregones tendentes a evitar el contagio publicados por la Real Audiencia entre 1629 y 1631.

Además, a los ya reseñados, todavía cabe añadir otro elemento complicador. A raíz de la guerra, el 23 de junio de 1628 el virrey había publicado una real cédula prohibiendo el comercio con Holanda e Inglaterra, que afectaba tanto a las mercancías como a las personas o embarcaciones de propiedad inglesa $u$ holandesa aunque estuviesen capitaneadas por patrones de distinta nacionalidad ${ }^{3}$. Pese a que entre los productos vedados en uno y otro caso no se incluía el trigo, es evidente que no resultaba ventajoso desplazarse desde tan lejanos países sólo para transportar el preciado cereal. En todo caso, las importaciones debieron resentirse por cuanto en octubre de 1630 los jurados solicitaron al rey que permitiera el acceso al puerto de naves holandesas. Aunque en esta ocasión Felipe IV accedió a la entrada de navíos de dicha o cualquier otra nacionalidad enemiga de la Corona, a condición de que su carga fuera exclusivamente de trigo $y$ de que no estuvieran tripulados por «rebeldes»,

«Illustre Marqués de los Vélez, primo mi lugarteniente y capitán general. Haviéndose visto lo que essa ciudad de Valencia me ha representado aserca de lo mucho que conviene acudir luego por todas las vias que se pudiere al reparo y provisión de trigos por hallarse con mucha falta dellos y que sería muy posible que de partes de contrabando y de enemigos acudiesen vaxeles con trigos propios y otros con agenos y que por no hallar otros navíos dexasen de traher los trigos en daño de la dicha ciudad, pues la hambre no sufre dilación, supplicándome sea servido tener por bien que desde luego guiéis y aseguréys las personas de qualesquier capitanes, patrones de naves y marineros que truxeren trigos a la dicha ciudad y los mismos trigos y vaxeles, aunque sean de contrabando, por el tiempo, modo y forma que por los fueros y privilegios está ordenado. Y visto lo referido y lo que vos también me havéys representado, en razón de la necessidad que padexe essa ciudad y

\footnotetext{
1. LAPEYRE, H.: La Taula de Cambis (en la vida económica de Valencia a mediados del reinado de Felipe II), Valencia, 1982, p. 132.

2. ACA CA. Leg. 838 , doc. $57 / 4$.

3. ACA CA. Leg. 576 , doc. $7 / 1,7 / 2$
} 
reyno en la falta de trigos, he tenido por bien, en ocasión tan apretada, dar licencia para que puedan venir ahí los trigos en navíos de contrabando, fábrica de Olanda, con que la jente que los navegare no sean olandeses ni de otras naciones enemigas de mi corona y con calidad que no puedan traher ningún otro género de mercadería. Y en esta conformidad es mi voluntad que lo permitáys asigurando y guiándolos el tiempo que ahí estuvieren para la venta de sus trigos» ${ }^{4}$

dos meses después, el 15 de diciembre de 1630, la imperiosa necesidad le obligó a hacer extensiva la concesión incluso a las embarcaciones guiadas por holandeses

«Illustre Marqués de los Vélez primo mi lugarteniente y capitán general. En consideración de la necesidad que padeçe essa ciudad y reyno con la falta de trigos, os escriví, como savéys, en carta de 28 de octubre pasado que tenía por bien dar licencia para que pudiessen venir ahí los trigos en navíos de contrabando fábrica de Olanda, con que la gente que los navegase no fuesen olandeses ni de otras naciones enemigas de mi Real Corona, y con calidad que no pudiesen traher ningún género de mercadurias y que en esta conformidad lo permitiésedes, asegurando y guiándolos al tiempo que ahí estuviesen para la venta de sus trigos. Y hagora, a suplicación dessa ciudad de Valencia, por cuya parte se me ha representado el apretado estado en que se halla por falta de los dichos trigos, es mi voluntad que podáys también guiar no sólo a los dichos navíos de contrabando pero también a la gente que los navegare, aunque sean olandeses; pero esto se entiende no haviendo otros navíos ni gente de que poderse valer en esta ocasión, con que, como está dicho, no traygan ningún otro género de mercadurias, que assí lo he mandado por mi Consejo de Estado. ${ }^{5}$

Por lo demás, junto al sistema de ayudas, fue necesario poner otros a contribución, como la compra directa de cereales por parte de la Ciudad mediante la solicitud al rey de licencias de «saca) sobre el trigo de los mercados próximos de Aragón y Castilla. Además, ante la persistencia de la gravedad, pese a todas las soluciones ensayadas, el Consell se vio obligado a dirigir una vez más su mirada hacia la que tantas veces le había sacado de apuros y continuaba siendo la isla del trigo: Sicilia. Ya desde 1626 se habian hecho llegar a Felipe IV voces cada vez más insistentes solicitando el restablecimiento del síndico ${ }^{6}$. Sirva de ejemplo la petición elevada el 9 de julio de 1630

«Señor. Per a remediar la gran necessitat de forment que esta ciutat patix, ninguna diligència pot ser a propòsit sinó trametre a Sicilia y Serdeña un síndich per a provehir-se per son medi de esta vitualla, y encara que los beneficis que de semblant tramesa y nominació de síndich an de resultar són tals que la justifiquen bastantíssimament, no res menys emperò estan impossibilitats de fer-la per aver-mos-ho manat prohibir Vostra Magestat. Y perquè en altra ocasió per haver paregut convenient manà Vostra Magestat dispensar en semblant prohibició ab sa real lletra de 20 de dehembre del any 1620 , en virtud de la qual fonch nomenat Gerónimo Alfonso, an cessat los motius que mogueren lo real ànimo de Vostra Magestat a fer semblant prohibició, suplicam quant humilment podem a Vostra Magestat, sia de son real servey manar veure y considerar lo memorial que presentam junctament ab esta, en lo qual se contenen les rahons que novament militen per a fer esta nominació per tenir a son càrrech la ciutat lo pastim general y en virtut delles concedir-nos facultat y licència per a

4. AMV. Cartas Reales, h3-8, fol. 245.

5. AMV. Cartas Reales, h3-8, fol. $244 \mathrm{v}$.

6. AMV. Lletres Misives, G3-59, sf. 
executar-la; y pux de ella resultarà a la ciutat lo benefici que en dit memorial se conté, la estimarem en singular gràcia y mercé de la real mà de Vostra Magestat.... ${ }^{7}$

Sólo ahora, cuando la necesidad empezaba a trocarse en hambre, el monarca admitió la designación de un síndico, cargo que finalmente recayó en Lucas Juan Navarro, quien, aunque en un primer momento se negó a aceptarlo arguyendo su delicada salud, finalmente se vio obligado a claudicar ante la insistencia de los jurados, alentados por la posibilidad de adquirir trigo más barato que el proporcionado por los mercaderes. ${ }^{8}$ Poco después, con idéntico propósito de agilizar las importaciones de Orán, en 1631 se nombró síndico de la plaza a Francisco Bayarri9. Finalmente, en situaciones extremas la Ciudad no dudó en acudir a procedimientos menos honestos, como el embargo de cargamentos que no le estaban asignados, al tiempo que la de atracción de grano del exterior se combinó con la adopción de una política proteccionista sobre aquellos productos que se cultivaban en el reino y que de alguna manera podían contribuir a paliar la falta de pan, en particular el arroz que tradicionalmente había actuado como sustitutivo ocasional. Ya el 3 de noviembre de 1630, a petición de los jurados, el monarca prohibió la extracción de arroz

«Magníficos, amados y fieles nuestros. Habiéndose visto lo que me representáys en uno de los cabos de vuestro memorial en razón de lo que conviene se prohiban las sacas de arroz desse reyno por suplirse con él mucho la falta que tiene de pan, tocándome, como me toca a mí y no a otro, la dicha prohibisión, scrivo a mi lugarteniente y capitán general sobre ello. De quien entenderéys la resolusión que he tomado en lo que me suplicáis... $\rangle^{10}$

Medida a la que ya había precedido la publicación el 3 de agosto del mismo año de un pregón en el mismo sentido, cuyo contenido se reiteró en otras cridas de 6 y 8 de marzo de 1631,15 de marzo de 1632 y 30 de mayo de 1634 .

Por lo demás, resulta importante señalar que la grave situación vivida por Valencia entre 1629 y 1631 aparece reflejada con nitidez en las curvas de Hamilton ${ }^{11}$, que traducen una escalada agresiva de los precios iniciada en 1628 , que alcanzaría su momento más crítico en la primavera de 1631 -situación de la que resultan expresivas las anotaciones del dietarista Vich en el sentido de que «vale el trigo a 17 libras y no se halla en el reyno' ${ }^{12}$ - para comenzar a descender en 1632 . Sin embargo, hay dos cuestiones que restan parte de representatividad a estas cifras. En primer lugar se trata de precios obtenidos a partir de la tasa que impuso el Consell en la venta de granos cuando, en realidad, fruto de todo momento de crisis, se desató la actividad de los especuladores, que vendieron el trigo muy por encima de las tasas, resultando muy poco efectivas las inspecciones temporales a casas, silos o bodegas de los sospechosos y los pregones

\section{Ibid.}

8. AMV. MC. reg. 157, sf, 26 noviembre 1630.

9. Ibid.

10. A.M.V. Cartas Reales, reg. h3-9, fol. 89v.

11. HAMILTON, E. J., El tesoro americano y la revolución de los precios en España, 1501-1650, Barcelona, 1975.

12. VICH, D y A, Dietario valenciano, 1619-1632, Valencia, 1921, p. 199. 
contra los acaparadores y revendedores de trigo, arroz y demás granos, que entre 1628 y 1634 se divulgaron con inusual insistencia ${ }^{13}$. E, incluso aceptando los valores tasados por el Consell, es necesario señalar que los trigos se cotizaron en Valencia a distinto precio según su procedencia. El de Cerdeña se pagó siempre por encima del originario de Castilla, Aragón y Andalucía, llegando en ocasiones a negociarse con una diferencia de varias libras. A lo largo de 1629 el trigo de Cerdeña se pagó a una media de 9 libras, en 1630 osciló entre 9 y 10 libras 5 sueldos, en 1631 entre 11 y 13 libras 5 sueldos y en 1632 entre 6 y 11 libras 12 sueldos 6 dineros. Por su parte, el trigo de Aragón o Castilla en 1629 se pagó a 8 libras, en 1630 entre 8 y 9 libras 11 sueldos, en 1631 entre 8 y 13 libras y en 1632 entre 7 libras 15 sueldos y 8 libras $^{14}$.

En todo caso, lo que realmente interesa resaltar de estos datos es que durante el cuatrienio estudiado los precios del trigo alcanzaron unas cotas sin precedentes en el siglo, de funestas consecuencias para las finanzas municipales porque su subida, lejos de comportar mayores márgenes de beneficios para el Consejo supuso importantes pérdidas. Aunque algunos años se liquidaron cereales con ganancia, otros se cedieron al mismo precio de coste e incluso en algún momento más bajos. Además, muchos de los pagos que exigió la política del trigo se efectuaron haciendo intervenir los fondos de que era depositaria la Taula de Canvis, arriesgada politica que desembocó inevitablemente en una falta de numerario.

\section{LOS ARBITRIOS FRENTE A LA CRISIS Y LA SOLUCIÓN FINAL}

Ante esta grave situación, la primera medida adoptada fue el recurso a la inflación. El Consejo municipal informó al monarca de la conveniencia de emitir nuevo vellón para la rehabilitación de la Taula, solicitud a la que Felipe IV accedió en enero de 1634 concediendo la acuñación de 50.000 libras y su renuncia al señoreaje en favor de la Ciudad $^{15}$. Pero la emisión de vellón iniciada a comienzos de 1634 suscitó inmediatas acusaciones de falsificación, que ya se habían hecho patentes desde el mes de junio del año anterior, y que determinaron la publicación de una serie de pregones tendentes a evitar el cambio de moneda con interés y a acabar con todo el vellón falso. El de 30 de junio de 1633 prohibía «tomar interés de plata valenciana y moneda de bellón por partida de Tabla, albaranes de Valencia y menudos $\rangle^{16}$. El de 7 de julio del mismo año especificaba que ni en los cambios de moneda «grosa» castellana, ni en los que se hacían para feria y para Madrid, Sevilla, Italia, ni otras partes, ni en las compras y ventas de ropa, ni en cualquier tipo de intercambio comercial podría existir diferencia de valor y estimación de la moneda de reales valencianos, «menuts», albaranes o partidas de Taula. Finalmente, atribuyendo gran parte de los abusos cometidos en este sentido a los corredors de orella, prohibía a los que no tuvieran licencia expresa intervenir en

\footnotetext{
13. Los datos han sido extraidos de los Manuals de Consells. regs. 155-159.

14. HAMILTON, E. J.: op. cit., p. 134.

15. ARV. Real. reg. 1380 , fol. 64.

16. ARV. Reales Pragmáticas impresas. reg. 968 , fol. 335.
} 
cualquier tipo de «cambis ferials», bajo pena de seis años de destierro de la ciudad y reino, 100 libras y suspensión de oficio. ${ }^{17}$

El 22 de septiembre de 1634 se hacía pregonar una nueva crida en la que, con el fin de «conseguir lo efecte de la exterminació y extinció de dita moneda», el virrey, de conformidad con el regente de la Real Cancillería y los doctores de las tres salas de la Real Audiencia, decretaba la obligación de manifestar, en el plazo de diez días, los «menuts falsos» ante unos puestos previamente designados para ello; ordenaba la publicación del contenido de la crida en todas las cabezas de partido o gobernaciones; obligaba a los encargados de recibir el manifiesto a retener la moneda falsa, anotando las cantidades declaradas por cada persona ${ }^{18}$; estipulaba las penas en que incurrirían aquellos que, concluidos los diez días, continuaran disponiendo de moneda falsa ${ }^{19}$; establecía una sanción de seis años de galeras o destierro a los presidios de Orán, más 50 ó 100 libras, según se tratara de plebeyo o persona que gozara de privilegio militar, para cualquiera que se encontrara fuera de la ciudad llevando consigo veinte reales de moneda falsa ${ }^{20}$; prohibía al cajero, contador y demás oficiales de la Taula de Canvis admitir moneda sin pesarla y examinarla previamente; estipulaba la distribución del resultante de las penas ${ }^{21}$; acordaba el carácter fiscal de los casos de contravención a la pragmática y por tanto que se pudiera proceder en ellos por mero oficio, sin instancia de parte privada; advertía que de las penas impuestas por este motivo no se podría hacer composición ni remisión; obligaba a los jueces a comunicar su conocimiento sobre alguno de los casos al virrey, abogado fiscal o cualquiera de los doctores del Real Consejo Criminal; ofrecía diferentes premios a quienes descubrieran algún delito de falsificación ${ }^{22}$ y finalmente designaba unas casas, asistidas por el notario correspondiente, en las que se podían manifestar todos los extremos contenidos en la crida.

Pero, realmente, la moneda acuñada en nada contribuyó a mejorar la situación, por lo que se hizo necesaria la adopción de medidas más enérgicas. Con el fin de agilizar todo tipo de negociaciones tendentes al desempeño de la Ciudad y la restauración del crédito, el virrey marqués de los Vélez, nombró una junta encargada de elaborar los expedientes oportunos. Resultado de sus numerosas reuniones los miembros de la misma alertaron sobre el grave estado por el que atravesaba la Ciudad, que calificaban como «el más calamitoso que ha tenido en tiempo alguno» por faltarle totalmente el crédito y no haber podido afrontar el pago de las pensiones de los censales. En ese momento las deudas se cifraban en 600.000 libras -resultado de la acumulación derivada de que desde muchos años atrás los gastos superaban en 20.000 libras a los

17. Ibid.

18. Wid., fol. 336 .

19. Ibid.

20. Jbid., fol. 337.

21. ACA. CA. Leg. 678, doc. $41 / 2$

22. ACA. CA. Leg. 678, doc. $37 / 2$. 
ingresos- de las cuales, según el informe elevado al monarca por el síndico Juan Lucas Ivars, 300.000 correspondían a particulares y las restantes procedían de albaranes

«Juan Lucas Yvarz, síndico y embaxador de la ciudad de Valencia, representando a Vuestra Magestad el miserable estado a que an llegado los propios y tabla de dicha ciudad a ocasión de haverse visto ser mucho mayor las responsiones y cargos que las entradas en cantidad de más de veinte mil libras en cada un año y que habiéndosse visto en notable descrédito por hallarse dever la dicha tabla seiscientos mil ducados, es a saver, los trecientos mil a particulares que han contratado con dicha tabla y los otros trecientos mil de albalanes que están oy por pagar entre sus vezinos» $\rangle^{23}$.

Urgía, por consiguiente, la adopción de soluciones que permitieran no sólo resolver el problema inmediato sino que a largo plazo consiguieran equilibrar el presupuesto. A este respecto, las primeras gestiones de la junta se orientaron a determinar la auténtica situación de las finanzas municipales. Así se pudo saber que en ese momento la Ciudad destinaba 100.000 libras a la administración de la carne y otras 100.000 a la adquisición de 12.000 cahíces de trigo; que las sumas de que era acreedora ascendían a 45.000 libras, que adeudaban los arrendatarios de las sisas, a las que cabía sumar 60.000 de diferentes deudores y 74.000 de la Generalidad, al interés del $5 \%$. Sin embargo, las dos primeras partidas tan sólo se consideraban recuperables a largo término mientras que «la cobranza de las 74.000 libras, quanto a la suerte principal por agora es impusible y quanto a los rédditos padece mucha dificultad porque en algunos años no se ha cobrado un real». ${ }^{24}$

Ante esta situación, la Ciudad carecía de propios, razón por la que se había visto obligada a obtener sus ingresos a partir de sisas e imposiciones, siendo éstas ya tan elevadas que se consideraba totalmente impracticable incrementarlas, medida correctora que todavía en la similar coyuntura de $\mathbf{1 6 1 2}$ había permitido paliar el déficit. Resultaba necesario, por tanto, buscar remedios nuevos. Pero tras muchas sesiones la junta no encontró otra solución viable más que la misma que ya había sido preciso adoptar en 1614, es decir la liquidación de la Taula, de manera que todo lo que la Ciudad quedara debiendo de restas y albaranes se cargara a censal al habitual interés del 5\%, renunciando el Municipio a los acostumbrados seis meses francos, corriendo por su cuenta el gasto de las escrituras de los censales que se hubieran de cargar, y quedando impedidos los magistrados de hacer uso de las sumas depositadas en la Taula a nombre de particulares.

«En espacio de muchos meses la junta extraordinaria que ha mandado formar el señor marqués de los Vélez, virrey y capitán general del Reyno, para tratar de los reparos de los daños de la Ciudad ha hecho quantas diligencias han sido posibles para averiguar el estado que sus cosas tienen y buscar los medios más oportunos para ocurrir al descrédito de la Tabla y paga de lo que deve y establecer a la ciudad una moral siguridad para que en lo porvenir no se vea en semejantes aprietos.Y para poder conseguir esto han concurrido las personas de quienes se han formado las juntas en que es forçosso que el débito de la tabla se

23. ACA. CA. Leg. 678 , doc. $37 / 2-3$.

24. ACA. CA. Leg. 678 , doc. $26 / 1$. 
extinga del todo y que para esto no hay otro medio que el extinguir la Tabla formando otra nueva como se hizo el año 1614 . Y que todo lo que la ciudad deviere de restas y albalanes esparcidos se lo cargue a censo a razón de a veinte mil el millar, que es el fuero común, acomodando a los que huvieren de cargar su dinero, en que no haya de tener la Ciudad el medio año franco que acostumbra y que corra por su cuenta de la Ciudad el gasto de las escrituras de los censos que se huvieren de cargar $\rangle^{25}$.

Asimismo, para poderse llevar a cabo la extinción el Municipio debería cargar a censal 500.000 libras cuyos intereses, sumados a las 20.000 libras que excedían las salidas a las entradas, supondrían un total de 45.000 libras, evitándose así una mayor acumulación de deudas. Junto a ello, los miembros de la junta propusieron diferentes medios tendentes a la recuperación económica. Consistía el primero en la imposición de seis sueldos de sisa sobre cada cahíz de trigo usado por los particulares, además de los dos sueldos y un dinero que ya pagaban; tres sueldos y siete dineros sobre el cahíz del trigo del pósito, además de los cuatro sueldos y seis dineros coñ que ya contribuían, quedando así igualada en ocho sueldos y un dinero por cahíz la sisa pagada tanto por los particulares como por el pósito. Con esta medida se esperaba conseguir una recaudación anual de 15.000 libras, juzgándose adecuada por no introducir novedades en su administración, no exigir mayores gastos ni salarios y no grabar más el alimento del pobre que el del rico. ${ }^{26} \mathrm{El}$ segundo medio propuesto consistía en que la sisa del vino de tres sueldos por libra que introducían los particulares para consumo propio y la de cuatro sueldos por libra que adquirían para revender se incrementara a particulares, taberneros y cosecheros a razón de un sueldo y seis dineros por cántaro. Con ello, además de evitarse los fraudes cometidos por los eclesiásticos en la refacción y repararse la injusticia que suponía que el vino de las tabernas -consumido por los más pobres- estuviera menos grabado que el destinado al uso en casas particulares, se pretendía elevar la recaudación de esta sisa - situada en ese momento en 15.000 libras - sin que los naturales del reino sufrieran por ello incomodidad alguna. La posibilidad de conseguir este incremento vendría demostrada por la comprobación de que en Valencia se introducían anualmente 10.500 pipas que con el nuevo impuesto reportarían 47.250 libras que, sumadas a las 7.000 que importaban las sisas de grueso y la del aguardiente supondrían un total de 54.250 libras.

Para conseguir el fin deseado, la recaudación de la nueva sisa debía regirse por una serie de capítulos elaborados al efecto. En ellos se disponía que cada cántaro de vino o vinagre que se introdujera en la ciudad pagara dieciocho dineros por cántaro, que el tabernero podría recuperar añadiendo dieciocho medidas al cántaro grueso, de manera que pesara veintiocho libras y una onza y media, según las condiciones siguientes: el vino de tres sueldos tendría cincuenta y cuatro medidas -treinta y seis por el valor del vino y dieciocho por la sisa-, estipulándose, además, una relación muy precisa del peso de la bota de vino de cada precio; en las tabernas no podría haber

25. ACA. CA. Leg. 678 , doc. $27 / 1-2$.

26. ACA. CA. Leg. 678 , doc. $29 / 1$. 
medidas diferentes a las sisadas; la sisa de grueso se pagaría además de los dieciocho dineros por cántaro; no sufriría modificación alguna la sisa sobre el vinagre pagada por los tintoreros, zurradores y «tapereros»; el vino transportado desde la contribución particular a la general se grabaría con seis dineros por cántaro mientras que el importado de Torrente seguiría pagando derecho doble; los taberneros continuarían beneficiándose de la acostumbrada refacción por las pérdidas que pudieran sufrir por la venta al por menor; se llevaría una contabilidad muy precisa del vino del que se despachara albarán denominado de canónigo, así como de la refacción a los exentos; los cosecheros de la ciudad y sus arrabales quedarían obligados a presentar el manifiesto del vino recolectado y pagar la sisa correspondiente; el vino procedente de fuera de la contribución pagaría sisa doble; antes de aplicarse la nueva sisa los arrendatarios de la ciudad restituirían las sumas cobradas por el vino que hubiera quedado por vender y se suprimirían todos los oficiales empleados en el cobro del gravamen, exceptuados los encargados de anotar las «sajetas» de las tabernas y de asistir a la casa de la sisa del vino; se aplicarían inviolablemente las penas previstas contra los defraudadores de las sisas del vino; se prohibiría introducir vino de fuera de la contribución sin licencia. previa de los jurados, bajo pena de 500 libras por la primera contravención, 1.000 por la segunda y otras mayores, a arbitrio de los jurados, por la tercera; se prohibiría la habitual práctica de los particulares de introducir vino para consumo propio y posteriormente vender el excedente a tabernas o neverías, bajo pena de pérdida del vino, así como de las galeras, coches o cabalgaduras en que lo hubieran transportado; los dieciocho sueldos que se pretendían imponer se pagarían previamente a la introducción del vino sin cargarlos a cuenta de la «rebusca», por constituir su supresión otra de las pretensiones perseguidas; y se mantendrían en vigor todas las disposiciones relativas a la prevención de fraudes. El memorial redactado al efecto concluía asegurando que con la imposición de estas medidas se podría conseguir el cobro de la nueva sisa con toda puntualidad, con un gasto inferior al generado por la recaudación de los impuestos existentes sobre el vino en ese momento y sin perjuicio alguno para la Ciudad: «Con lo que se ha dicho la administración de este derecho se llevará con mucha puntualidady todo lo que prosediere dél se cobrará sin que la Ciudad tenga un maravedí de pérdida y el dia que acaba el año tiene todo su dinero cobrado sin que le quede deuda y con menos gasto de lo que hoy tiene» ${ }^{27}$.

El tercer medio consistía en que la Ciudad arrendase las mesas de las carnicerías los viernes, sábados y demás vigilias, del mismo modo que lo hacía en Cuaresma, expediente con el que se esperaban conseguir ingresos por valor de 100 libras. El cuarto suponía suprimir la sisa de la carne a cambio de obligar a los eclesiásticos a contribuir en el pago de las imposiciones durante quince o más años, debiendo obtener a tal efecto el necesario breve papal, o que al menos se tomara asiento con los eclesiásticos por vía de encabezamiento. Caso de no conseguirse ninguno de estos propósitos se probaría el medio del encabezamiento de las casas de los particulares, arbitrio mediante el que se esperaban obtener anualmente 54.000 libras, que restadas 10.000 por las que se pudie-

27. ACA. CA. Leg. 678 , doc. $29 / 6$. 
ran dejar de cobrar, supondrían alrededor de 45.000 , que reportarían un beneficio de 13.000 libras respecto a las sumas ingresadas a partir de la sisa de la carne, situada en cerca de 30.000 libras.$^{28}$ El procedimiento a seguir quedaba recogido en la «Instrucción para la diligencia del encabezamiento» redactada al efecto. En ella se disponía que, determinada la relación de personas que habitaban cada casa a partir del libro de comuniones, se comunicara a sus dueños el día que se llevaría a cabo la inspección. En tal momento se explicaría al propietario la grave situación financiera de la ciudad y se le presentaría la relación de todas las sisas con las que contribuía para su alimentación, así como la intención de sustituirlas por el pago de una cantidad anual.

«Al dueño de cada casa se le ha de representar el miserable estado de la Ciudad y cómo son tantos los pechos que pagan sus moradores que no es pussible sufran otros sobre ellos. $Y$ assí es fuerça buscar nuevos expedientes y el que se ofrece es el encabeçamiento. Y para que se entienda la comodidad dél se han de representar las sisas que pagan, que son por cada cahiz de trigo, dos sueldos y un dinero los casolanos y los que compran de la fleca seys sueldos y ocho dineros; dos sueldos por cada arroba de azeyte; por cada tocino que se mata en casa quatro sueldos y medio y si se compra por menor quatro libras; y en cada libra de ternera por lo menos un sueldo; en cada libra de vaca por lo menos ocho dineros; en cada cabrito dos sueldos y tres dineros; y en cada libra de carne de macho diez dineros y un dinero más de sisa vieja; y en cada libra de carnero quinze dineros, catorze de sisa nueva y uno de sisa vieja. Y que la Ciudad trata de quitar todas estas sisas aligerando dellas a sus moradores, solamente con que le paguen cada un año por tercias anticipadas lo qque importa la sisa de carnero y macho que comen cada día, no contando los días de ayuno, vigilias y Quaresma, aunque la gasten, sino tan solamente por ducientos veynte y cinco días que hay de carne, con lo qual podrá la Ciudad, según se espera, acudir a sus débitos y responsiones, y sus naturales y habitadores quedarán tan aligerados como se dexa considerar». ${ }^{24}$

\section{Ibid.}

29. Esta última propuesta provocó el inmediato rechazo de los hombres de negocios con intereses en tales casas de feria, quienes elevaron al rey dos memoriales sucesivos. En el que la documentación recoge como «primer memorial» se pronunciaban en los siguientes términos: «Los hombres de negocios que tienen casas de feria en la ciudad de Valencia offrescen que porque no se haga novedad en ellas sino que se queden como oy extán, prohibiendo que los que huvieren de dar y tomar a cambio en la ciadad y reyno de Valencia no puedan hacer los despachos en otras partes ni para otras ferias ni plazas más de la de Medina del Campo. que es la que siempre se ha acostumbrado, darán y corresponderán en cada feria la tercena parte de los aprovechamientos y responsiones limpia para el real patrimonio de Su Magestad de los gastos y salarios de officiales que tienen que llevar los libros y passar las escrituras y ajustar las responsiones y quentas de cada una, y de la assistencia y occupación personal de los dueños de las dichas casas, para los quales officiales, gastos y ocupaciones dizen han de servir las otras dos partes, quedando (como está dicho) la tercia parte en limpio para el real patrimonio de Su Magestad y que se les dé privilegio o otro despacho para los que oy iienen la negociación y administración de las casas de feria y para los que les sucedieren en ellas». Y con idéntico propósito de conseguir el favor real a cambio de una compensación cconómica redactaron un segundo memorial en el cual «offrescen para que se les concedan perpetuamente las casas de feria a las ocho que oy ay privative y distinctamente a otros pard ellos y sus successores tres mil ducados cada año y luego 40.000 reales y dentro de un año del dia que se les diere el privilegio otros 40.0000 reales, y que no puedan hazer letras ni despachos feriales que tengan recurso o retorno de otra parte ni para otra feria sino a Medina del Campo los vezinos y moradores en dicho reyno, y atue no hayan. de pagar por la media annata más cantidad que mil reales». ACA. CA. Leg. 678, doc. 32/8. 
A continuación se tomaría declaración de la carne consumida diariamente, anotando con todo detalle circunstancias tales como la presencia de ayos y criados a los que se diera o no de comer o el consumo de las personas exentas. Consideración aparte merecerían las posadas y mesones, de incierto número de comensales, a los que se aplicaría un «tanteo» presuponiendo un gasto diario de tres dineros por persona, exceptuados los exentos. ${ }^{30}$ El quinto medio contemplaba la persistencia del control del amasijo por cuenta de la Ciudad modificando sus capítulos en aras de su mejor ejecución y de evitar los inconvenientes evidenciados por la experiencia pasada, medida con la que se esperaban ingresar 10.000 libras. El sexto proponía que las mesas de las carnicerías no se arrendaran gratuitamente sino mediante el pago por parte de los arrendatarios de una suma proporcional a su valor; e igualmente se cobrarían 20 libras por las corredurías de «oreja» y 12 por las de «cuello» que quedaran vacantes, que conjuntamente podrían reportar 2.500 libras anuales. El séptimo sugería que la Ciudad tomara por su cuenta las casas de feria de Medina del Campo suplicando al rey la concesión de su estanco, procedimiento que, sin causar perjuicio a los particulares, supondría un beneficio de 12.000 libras. ${ }^{31}$

En opinión de los expertos, la aplicación conjunta de todos estos medios reportaría a la Ciudad una renta de 53.000 libras anuales que, sumadas a las 65.000 que se esperaban obtener del encabezamiento, permitirían no sólo hacer frente a las 45.000 libras sino incluso aportar un excedente de 20.000 libras con las que se podrían ir pagando las pensiones de los censales. Pero para conseguir este propósito se consideraba preceptivo que el monarca concediera a la Ciudad el aplazamiento de los pagos durante seis meses, cobrando así los acreedores con retraso pero con seguridad, debiendo destinarse la cantidad restante a aperturar la Taula nueva.

Por otro lado, habiendo mostrado la experiencia que la mayor parte de los daños padecidos eran atribuibles a la deficiente gestión de los oficiales, sin que en ningún momento se hubieran adoptado medidas para acabar con la situación,

«Y por que se ha experimentado que la mayor parte de los daños que la ciudad padece ha nacido de la remisión de sus officiales que ha muchos años que pudieron antever el estado que ha venido, pues no pudieron ignorar que era menos lo que tenía de renta que lo que respondía cada un año. $\mathrm{Y}$, con todo, hasta que se ha seguido la última imposibilidad en que se halla no han tratado del reparo del daño, ha parecido que para en lo porvenir se les deven establecer nuevas obligaciones y apretar con imposición de penas las que ya tienen por los capítulos del quitamiento y por las ordenaciones de la Tabla... $\rangle^{32}$

planteaban también la urgencia de que se tomasen las siguientes: que anualmente el primer día de junio el racional consignara al clavario de censales las cantidades necesarias para satisfacer el pago de las pensiones de los censales y al clavario común exclusivamente 20.000 libras para gastos ordinarios y extraordinarios, además del pago de los

30. ACA. CA. Leg. 678 , doc. $37 / 4$.

31. Ibid.

32. ACA. CA. Leg. 678 , doc. $37 / 2-4$. 
réditos de los censos, debiendo entregar las rentas sobrantes al clavario del quitamiento para redimir éstos. Pero en caso de no disponer la Ciudad de rentas suficientes para distribuirlas de este modo, el racional consignaría en primer lugar al clavario común las sumas necesarias para gastos ordinarios; después al clavario de censales las cantidades precisas para asumir los réditos; y sólo si restara alguna renta se destinaría al clavario común para gastos extraordinarios, por estimarse que no se podía atender a éstos en tanto no quedaran cubiertos los más perentorios. Se contemplaba, asimismo, la exigencia de que la Ciudad despachara albaranes para el pago de los réditos de los censos y los gastos ordinarios, quedando éstos, por el contrario, prohibidos cuando se tratara de gastos extraordinarios, en cuyo caso los jurados, racional y síndico deberían despachar provisiones, en cuya ejecución quedaría obligado el clavario común a pagar por la Taula a las personas afectadas a partir de la cuenta destinada a los gastos extraordinarios; se proponía la prohibición de que el clavario común girara por el banco municipal partida alguna bajo pena, extensiva al regente del libro mayor y a los escribanos de los libros del mismo, de privación de oficio y salario; que, en lo sucesivo, bajo ningún concepto el racional despachara albaranes privados, no pudiendo ser éstos admitidos por el cajero bajo las penas anteriores, y tampoco despachara albaranes llamados de bolleta que excedieran de 100 libras; que, si la Ciudad precisara para gastos extraordinarios una cantidad superior a las 20.000 libras consignadas al clavario común, éste no pudiera percibir suma alguna procedente de la clavería del quitamiento debiendo ser cargada a censo. Sólo en caso de no haberse consignado al clavario común las cantidades estipuladas podría obtener subvenciones de otras claverías siempre que no excedieran de 20.000 libras y con la obligación impuesta de restituirlas al clavario de quien las hubiera recibido.

Se sugería, además, que el racional y el síndico del racionalato, transcurrido un año desde la percepción de las consignaciones, realizaran las diligencias pertinentes para que se restituyeran las deudas a la Ciudad; que bajo ningún pretexto pudieran extraerse los albaranes tras haber sido ingresados en la sacristía; que cualquier insaculado que contraviniera los referidos capítulos incurriera en pena de privación de oficio y salario por un año, quedando, además, inhabilitado para desempeñar cargo alguno en la Ciudad, extraído de la bolsa y declarada vacante su plaza; y que los jurados, racional, síndico y demás oficiales de la ciudad, transcurrido un mes de la conclusión de su cargo, fueran sometidos a residencia por el juez visitador a quien el rey encargara tal misión

«Que el racional y síndico del racionalato, cada uno según la función tocante a su officio, dentro de un año de pasados los plaços de las consignaciones hechas a los clavarios de censales, común y del quitamiento hayan de hazer las diligencias respectivamente devidas para que la ciudad con todo effecto esté pagada, o conste no ser pagador el deudor, so las penas que luego se declararán.Que los albalanes que una vez se huvieren encerrado en la sacristía y cortado, por ningún camino o causa, por inopinada o precissa que sea, se puedan sacar ni reparar. Que los jurados, racional, síndico, clavario de censales, caxeros de gruesso y qualesquier personas de las que están insaculadas que contravinieren a los referidos cargos o alguno dellos incurran en pena de privación de officios y de los salarios de ellos por 
un año, los quales hayan de restituir sí los huvieren cobrado. Y demás desto queden inhabilitados para qualesquier oficios de la ciudad y sean borrados del libro de la insaculación y queden vaceas sus plaças para que otros las ocupen. $Y$ que estas mismas penas incurran los referidos officiales aunque la contravención la hayan cometido los subtitutos por ellos nombrados y las incurran los mismos substitutos. Y últimamente, que los jurados, racional, síndico y demás officiales de la Ciudad por el tiempo de un mes de acabados sus officios hayan de estar en residencia, la qual se les haya de tomar breve y sumariamente por el juez visitador que Su Magestad fuere servido de nombrar con la commisión que para ello huviere menester $y$ acostumbran tener semejantes juezes visitadores $\rangle^{33}$.

Se incluía, por último, la propuesta de la necesidad de adoptar medidas para prevenir fraudes en el pago de las sisas de la carne, pan y otras muchas. ${ }^{34}$

Así las cosas, en misiva de 8 de noviembre de 1633 el monarca ordenó a los jurados que designaran como embajador a una persona que hubiera participado activamente de las reuniones de la junta y que de este modo pudiera aportar su experiencia y amplio conocimiento del tema. Para tal misión los magistrados municipales designaron a Juan Lucas Ivars, síndico de la Cámara y miembro asiduo de la junta. Aunque en principio su partida a la corte debía ser inminente, las dificultades suscitadas por determinados puntos particulares y los reparos interpuestos por la Ciudad contra lo que consideraba una lesión de sus preeminencias y jurisdicción dilataron la toma de decisiones. En efecto, en el seno del Consejo General habían suscitado un vivo rechazo las propuestas relativas a la imposición de nuevas sisas en el trigo y en el vino pretextando no haber sido consultado sobre esta cuestión, cuya competencia le atribuian los fueros y privilegios, por lo que exigía la búsqueda de otras soluciones

«...y haviéndose resuelto entre otras cosas que se inpusiesen seis sueldos de sisa en cada caíz de trigo, más de la inpuesta, y mudada la sisa del vino por cántaros y no en moneda, haviendo approbado los jurados dichos dos arbitrios y puesto en execución el del trigo, el Consejo General no consintió en ninguno dellos, con solo pretexto de que con él no se havían consultado, tocándole por fueros y privilegios. Antes bien, resolvió el dicho Consejo se buscasen otros arbitrios, para lo qual nombró dies eletos que confiriessen con los jurados, los quales después de varias y diversas juntas juzgaron por convenientes y que se deurían sacar al Consejo General los arbitrios contenidos en un papel... $\rangle^{35}$

Así pues, como refiere el documento, los consejeros designaron a diez electos que, reunidos con los jurados, propusieron nuevos arbitrios «los quales no se sacaron al Consejo General porque de la vista dellos con el virrey se entendió era orden de Vuestra Magestad no se sacaran hasta haverse consultado». ${ }^{36}$ Figuraban entre éstos la eliminación de las sisas sobre la carne por ser las que más beneficiaban a los eclesiásticos y exentos; la aplicación de una nueva sisa de catorce sueldos sobre el cahíz de trigo, que reportaría unos ingresos de 43.400 libras; la imposición de cuatro sueldos y

33. ACA. CA. Leg. 678 , doc. $25 / 2$.

34. Ihid.

35. ACA. CA. Leg. 678, doc. 34/4.

36. ACA. CA. Leg, 678, doc. $25 / 2$. 
medio más sobre la sisa del vino, lo que permitiría ingresar 13.000 libras; el arrendamiento del amasijo, que aportaría 12.000 libras; el monopolio sobre las casas de feria, que supondría 12.000 libras; la aplicación del encabezamiento, que permitiría incorporar otras 12.000 libras; el arrendamiento de las carnicerías en Cuaresma y períodos de ayuno, que supondría 1.000 libras; la imposición de una nueva sisa de seis dineros por libra sobre el corte de tela, que importaría 6.000 libras; la adición de una sisa de seis dineros por libra del sebo que el administrador vendía a los cereros, con lo que se conseguirían aumentar 500 libras; el pago por el corralero de dos dineros más de lo que pagaba por cada res que mataba, que reportaría otras 500 libras; la imposición de seis dineros al carnicero por cada res que cortara, en concepto de alquiler de las mesas, que supondría 1.500 libras; la recuperación de las sumas adeudadas a la Ciudad lo que permitiría aliviarla de 5.000 ducados de responsiones anuales; el destino del nuevo impuesto del trigo, en el que contribuían los eclesiásticos, a quitar censales, que permitiría al Municipio disponer de 450 libras seguras; y la eliminación de los salarios destinados a la recaudación de la sisa de la carne. Pero junto a ellos, como ocurriera con la junta designada por el virrey, también consideraron como mejor solución la liquidación de la Taula y la erección de otra nueva. ${ }^{37}$

Por lo demás, de las restantes propuestas elaboradas por la junta extraordinaria los electos del Consejo consideraron aceptables la mayor parte. No obstante, además de la omisión del artículo relativo a que si el clavario común necesitara de mayores sumas que las 20.000 libras asignadas para gastos extraordinarios no le pudieran ser aportadas por otras claverías, presentaban dos discrepancias significativas. Por un lado, respecto al apartado relativo a que el racional no pudiera despachar albaranes privados introducían la excepción de que pudiera hacerlo en dos casos: para subvenir a los gastos del convento de San Gregorio y en caso de que, haciendo uso de la facultad otorgada por el fuero 26 de las Cortes de 1604 y por el capítulo 18 del quitamiento, acordaran enviar un embajador a la corte. La segunda modificación afectaba a las penas a aplicar a los insaculados por incumplimiento de los capítulos, que quedaban suavizadas al estimar suficiente que se contemplara sólo la aplicación de penas proporcionales a los delitos, quedando así suprimidas, al menos explícitamente, la privación de oficios y de salarios, la inhabilitación para el desempeño de otros oficios y la extracción de las bolsas de insaculación

«Que los jurados, racional y síndico, clavarios de censales, caxeros de gruesso y qualesquier personas de las que están inseculadas que contravinieren a los referidos capítulos incurran cada uno respectivamente en las penas contenidas en los dichos capítulos, según la qualidad de las materias de la contravençión, con conoscimiento de causa ${ }^{3 *}$

Por su parte, también los jurados elaboraron un memorial que, bajo el título de «Reparos que se hacen por los jurados de la ciudad a algunos de los aspectos resueltos por la junta extraordinaria», planteaba la necesidad de introducir modificaciones a

37. ACA. CA. Leg. 678, doc. 35/2.

38. ACA. CA. Leg. 678 , doc. $36 / 2$ 
algunas de las propuestas de la junta designada por el virrey por considerar que entraban en colisión con sus tradicionales preeminencias y privilegios, otorgadas por fueros, privilegios y cartas reales, para el gobierno de la Ciudad. A este respecto, si bien admitían su conformidad con los restantes artículos, advertían la necesidad de suprimir la parte penal del capítulo relativo a la prohibición de valerse del procedente de las sumas cargadas en la Taula hasta que se hubiera producido su ingreso efectivo en la misma. También manifestaron su desacuerdo con la supresión de todos los oficios relacionados con el pago del derecho del vino considerando necesario el mantenimiento de al menos un encargado de llevar el libro en el que se registrara la sisa de grueso y otro de asistir en la casa de la sisa del vino; la conveniencia de que caso de tenerse que ejecutar alguna pena corporal relacionada con el amasijo fuera competencia del justicia criminal según disponían los fueros; la supresión de la figura del administrador para que junto con los jurados pudiera juzgar los fraudes; la moderación de las penas a los of iciales fraudulentos en materia de amasijo; la concesión a los deudores de un plazo más amplio que el propuesto para restituir las sumas adeudadas; el mantenimiento de las atribuciones del racional en relación con la emisión de albaranes privados esgrimiendo que «de quitarse esta facultad a la Ciudad en algunas occasiones podría resultar algún gravissimo daño y perjuhicio al bien comín»; la eliminación de las propuestas relativas a la prohibición de que el clavario del quitamiento pudiera subvenir al clavario común por haber mostrado la experiencia resultar urgente en muchas ocasiones atender los gastos generados por esta clavería. Asimismo, como ya hicieran los consejeros, insistían en la necesidad de suprimir, por excesivamente rigurosas, las penas de inhabilitación y desinsaculación de los oficiales corruptos, considerando suficiente contemplar la aplicación de penas proporcionadas a los delitos cometidos; la omisión del sometimiento a residencia de los oficiales por estimar que ya los fueros contemplaban esta facultad por parte del monarca siempre que lo creyera necesario; y la eliminación de las penas propuestas en el último capítulo del memorial elaborado por la junta extraordinaria

«Adviértese que la pena de perdición de officios, hinhabilitación y de ser borrados de la lista de insaculación generalmente puesta en el dicho memorial ... parece muy rigurossa y que bastará que ésta la tenga cada uno según la calidad de las materias de la contravención con conocimiento de causa, aunque se pueda estender a ser borrados de la insaculación y que la pena corporal y personal bastará que la incurran los substitutos y no los que los nombraren. Últimamente, se advierte que lo contenido en el último capítulo de dicho memorial en quanto se dize questén en residencia los officiales por tiempo de un mes, no es necessario dicho capítulo supuesto questá prevenido por fueros del reyno y que Su Magestad tiene libre facultad, siempre que fuere de su servicio, mandar residenciar a sus ministros y officiales y premiar a los buenos y castigar a los malos. $\rangle^{39}$

A su vez, tampoco la respuesta de esta última junta, recogida en el memorial titulado «Satisfacción a los reparos que los officiales de la Ciudad han hecho a algunos de los cabos resueltos por la junta extraordinaria», ${ }^{40}$ se hizo esperar, limitándose, en

39. ACA. CA. Leg. 678 , doc. 42.

40. ACA. CA. Leg. 678, doc. 25/15. 
esencia, a desestimar la justificación de todos y cada uno de los reparos interpuestos por los magistrados municipales, de los que tan sólo el relativo a la sustitución del término «albaranes privados» pareció aceptable.

Ante tan considerable avalancha de memoriales con propuestas y contrapropuestas, en misiva de 9 de febrero de 1634 el virrey, marqués de los Vélez, optó por remitir al monarca todos los expedientes elaborados junto con los reparos interpuestos por la Ciudad, acompañados de su parecer particular sobre cada uno de ellos

«En cumplimiento de lo que Vuestra Magestad me mandó por la real carta de ocho de noviembre del año próxime passado ordenándome dixese a los jurados de esta ciudad hiciessen nombramiento de una de las personas de la junta en que e tratado los expedientes para el reparo de su tabla para que los llevase a Vuestra Magestad, y siendo persona plática en las materias tratadas pudiesse satisfacer qualquier duda que ay se pueda offrecer para que con más vrebedad se consiga la resolución que Su Magestad se sirviere tomar, les insinúe la voluntad de Vuestra Magestad. Y ellos nombraron a Juan Lucas Ybars, síndico de la cámara de la ciudad, que a sido uno de los de la junta y a quien tienen por muy inteligente y a propósito para encargarle, como lo an hecho, la solicitud de este negocio ( y yo espero acudirá a él con mucho celo) que es de tal calidad que aunque en mi carta de 25 de octubre del año passado en que propusse a Vuestra Magestad tres personas de la junta pareciéndome eran las más capaçes de las materias para que Vuestra Magestad mandase a los jurados nombrassen una dellas para llevar los papeles dixe estavan resueltos y ajustados los expedientes que se devían proponer a Vuestra Magestad. Después se an offrecido tantas dificultades, demandas y respuestas sobre puntos particulares de reparos que la Ciudad a hecho pretendiendo se encontravan con sus preheminencias y juridición que de ninguna manera se an podido allanar de suerte que se consiga el fin de su remedio. Y por no diferir más lo que tanto importa e resuelto de remitir a Vuestra Magestad todos los dichos expedientes y los reparos de la Ciudad, los capítulos que se an hecho en orden a su conserbaçión y buena execución de las sisas e impossiciones y, en particular, los que an parecido forçosos para cerrar la puerta a que la Ciudad se entre en la Tabla, que es el camino por donde, sin sentirlo, de muchos años atrás se a venido perdiendo asta llegar al estado pressente, que es el más misserable en que una república se puede ver...». ${ }^{41}$

En estas condiciones, el 12 de febrero de 1634 partía de Valencia Juan Lucas Ivars como embajador ante el rey con un paquete portador de catorce propuestas diferentes. Por su parte, recibido el memorial con los expedientes presentados por éste y vistas también las propuestas de la junta nombrada por el virrey, en la consulta elevada al monarca el 9 de marzo de 1634 el Consejo de Aragón estimó especialmente urgente la liquidación de la Taula y la erección de otra nueva, medida que contaba con la aquiescencia unánime del virrey, la junta extraordinaria, las tres salas de la Real Audiencia, los jurados y los diez electos del Consejo General «mientras se van viendo y especulando los demás papeles de arbitrios que ha remittido el virrey con el dicho síndico para que la ciudad pueda subvenir por medio dellos o de otros que parescieren a propósito para salir de tan grande empeño como en el que oy se halla». ${ }^{42}$ La respuesta de Felipe IV a esta consulta no pudo ser más astuta:

\footnotetext{
41. Ibid.

42. BUV. Mss. 253, fols. 198-199.
} 
«Como parece. Pero será bien que el Consejo esté atento a introducir por la mano que ansí viniere para tenerla yo mayor en la hacienda y gobierno de aquella ciudad, pues en occasiones como ésta se puede hacer con tanta facilidad. Y assí lo encargo al Consejo y que me dé muy particular quenta de lo que se podrá encaminar en orden a esto quando me consulte sobre los medios. Y esto es tan importante quanto se vee que tiene de dificultad o que se desea encaminar en las ciudades de la Corona de Aragón por la poca dependencia que tienen». ${ }^{43}$

Se trataba, en definitiva, de aprovechar las difíciles circunstancias financieras por las que atravesaba la ciudad para reforzar la autoridad monárquica. Pero, entretanto se velaba por la consecución de estos objetivos, se hacía necesario dar una respuesta inmediata a la que se consideraba la medida prioritaria: la liquidación de la Taula de Canvis. A este respecto, el 20 de marzo de 1634 el monarca escribió a los jurados expresando su conformidad con la solución:

Magníficos, amados y fieles nuestros. Hase visto vuestra carta de nueve de passado y el memorial tocante a los arbitrios que se os ofrescen haevéys imbiado a Joan Lucas Yvars, vuestro syndico con los papeles de esta materia. Y porque entre los medios que proponéys es uno el de la extinción de la tabla y eregir otra nueva y ser el que más preme, he tenido por conveniente que se extinga en la conformidad que lo escrivo en carta de la misma fecha desta al marqués de los Vélez, mi lugarteniente y capitán general de esse reyno, de quien lo entenderéys. Y aquello executaréys puntualmente, toda duda, consulta, difficultad y otro cualquier impedimento cessante» $\rangle^{44}$.

Como deja entrever el documento la extinción debía llevarse a efecto según los capitulos redactados por una junta reunida en Valencia bajo la presidencia del virrey, a los que se añadieron por parte del Consejo algunas matizaciones y correcciones. En conjunto se estableció que el «cierre» debía llevarse a cabo de acuerdo con once artículos que el propio monarca dio a conocer al marqués de los Vélez en carta de 20 de marzo de $1634^{45}$. En ella ordenaba Felipe IV que se hiciera un pregón indicando la fecha de la quiebra de la Taula, a partir de la cual no se deberían admitir los pagos realizados por ella o con albaranes; que desde este momento la Ciudad admitiera el «cargamiento» de restas o albaranes a razón del $5 \%$, sin los seis meses francos; que a los que quisieran cargar sus restas la Ciudad les concediera crédito en la Taula para poder usar de ellas a su voluntad; que puesto que las partidas destinadas a la feria de Medina del Campo no podrían ser ingresadas en efectivo, que no les obligara a pagarias sino dos ferias después del cierre con los intereses correspondientes; que la Ciudad se obligara a admitir por Taula los plazos que cumplieran después de su extinción. Bajo pena de privación de sus respectivos oficios, prohibia a los clavarios entrometerse en los fondos de la Taula y al regente del libro mayor permitir tales intromisiones. Al último se le obligaba a que al principio de su oficio prestara juramento de que, caso de que la Ciudad necesitara urgentemente, para el abastecimiento de trigo, carne o cualquier

43. AMV. Cartas Reales, h3-9, fol. 174v-179.

44. ACA. CA. Leg. 678 , doc. $25 / 17$.

45. ACA. CA. Leg. 678 , doc. 25/1. 
otra vianda, dinero efectivo, hubiera de obtenerlo cargándolo a censal; exigía a los cajeros de «grueso» revisar cada cuatro meses las cuentas de los clavarios de censales y comunes y de los administradores de la Lonja Nova; prohibía a los jurados, racional y síndico hacer provisiones por las cuales se pervirtiera el orden de «boixart» para el «quitamiento» de cualquier censal, bajo pena de privación de oficio y de inhabilitación para concurrir a otros; establecía la obligación de la Ciudad de designar personas encargadas de examinar, y en su caso cortar, la gran cantidad de «menudos» falsos que circulaban por la ciudad; y renovaba la prohibiciones, penas y disposiciones de los capítulos del quitamiento elaborados por Felipe III y relativos al buen funcionamiento de la Taula ${ }^{46}$.

A éstos, bajo el encabezamiento de «Capitulos que se añadieron a los que vinieron de Valencia para la extinción de la tabla de aquella ciudad y erección de otra nueva» se sumaron otros, no contemplados en las juntas de Valencia, por los que se obligaba a los jurados, racional y síndico a presentar todos los años por San Juan un balance ajustado de las entradas y salidas efectuadas a fin de detectar la situación de la Taula con tiempo suficiente de adoptar soluciones eficaces; concedía seis meses de suspensión en el pago de los censales para que la nueva Taula empezara su funcionamiento con cierto alivio; ordenaba que el dinero que se encontrara en ella a su nombre, procedente de los receptores y tesoreros de la real hacienda, no quedara sujeto a «cargamiento» sino que pasara directamente al libro de la nueva Taula, para poderse valer de él sin pérdidas; finalmente, encargaba que la ejecución de todos estos capítulos se llevara a efecto con la máxima brevedad ${ }^{47}$.

El 1 de abril de 1634 empezaron a ejecutarse los primeros acuerdos tendentes a la liquidación de la Taula. Sin embargo, la negociación fue larga y laboriosa. Al parecer la Taula Novissima comenzó a funcionar desde el 13 de abril de 1634. Pero, según se desprende de algunas disposiciones, la extinción definitiva de la Nova no se ultimó hasta 1649 en que se erigió oficialmente la Novíssima. Durante el período que media entre ambos años se produjo la coexistencia de las dos: Nova y Novíssima ${ }^{48}$. Sólo después de puesta en marcha la liquidación de la Taula se atendió al contenido de los expedientes que Juan Lucas Ivars había entregado a Felipe IV en el mes de febrero. El 16 de mayo de 1634 el Consejo de Aragón remitió un informe al rey con su parecer. En él aceptaba la imposición de todos y cada uno de los arbitrios salvo la cuestión de las corredurías porque «acordó el Consejo haviendo visto los fueros que no ay que tratar de las corredurias porque tiene inconveniente y es de muy poca utilidad»; el monopolio de las casas de feria por parte de la Ciudad por considerar que «en esta materia de las casas de feria se han de reconoscer papeles que se han presentado por hombres de negocios contradiziendo esto que la ciudad pide y otros que ha embiado el virrey y con brevedad consultará el Consejo a Vuestra Magestad lo que en orden a ello se le

\footnotetext{
46. Carreres ZaCares, S.: La Taula de Cambis de Valencia, 1408-1719, Valencia, 1957, p. 64.

47. ACA CA. Leg. 678, doc. 24/1.

48. BUV Manuscritos, reg. 701 , fols. 144-162.
} 
offresciere»; y el relativo a la obtención de un breve papal por el que los eclesiásticos se vieran obligados a contribuir por un plazo de 15 años refiriendo que « aunque el virrey y junta concuerdan en todo con lo que la ciudad supplica en este capitulo, el Consejo tiene esta materia por de mucha consideración y assi se reserva para mayor inspectión della el consultar a Vuestra Magestad lo que tuviere por conveniente, como lo hará con brevedad»"

Los restantes adquirieron vigencia a partir de la pragmática de 6 de noviembre de $1634^{50}$ que, para infundir mayor efectividad a estas medidas, añadía unos «Capitulos para prevenir que no se cometan fraudes como hasta oy en las imposiciones y sisas de la ciudad》. En ellos se contenía una larga serie de prohibiciones, condenas y advertencias. Entre las primeras se incluían la recepción de mercancías, aunque fueran acompañadas de su correspondiente albarán, por parte de alquerías de la huerta y arrabales; la introducción ilegal de carne de carnero, macho cabrío, vaca, cabrito o ternera; y la circulación de trigo, pan o harina sin los albaranes pertinentes. A continuación se estipulaban duras penas contra quienes incurrieran en delito en materia de avituallamiento. Así, los dueños de los coches utilizados en la introducción clandestina de vituallas serían castigados con un mes de cárcel por su primera infracción, con azotes por la segunda y con destierro por la tercera. Por el delito de molienda de trigo con albarán de «avenido», además del cierre del molino por dos meses, incurrirían en pena de 50 libras por la primera contravención, 100 por la segunda y destierro por la tercera. A su vez, el credenciero del almudín que osara despachar albaranes a cualquier molino cerrado sería penado con 50 libras por cada albarán. Finalmente, se recomendaba que se cumplieran inviolablemente los capítulos relativos al amasijo; que no se destinaran para gastos extraordinarios más de 20.000 libras, debiéndose cargar las restantes a censal, y que se hiciera juicio de residencia a los jurados, racional y síndico.

Con todo, la resolución de estos aspectos dejaba pendiente el vidrioso asunto de las restas de la Taula pertenecientes al patrimonio real, que el monarca había dispuesto que pasaran íntegramente a la nueva Taula. Las quejas que suscitó la pretensión real pudieron ser acalladas en un primer momento por el virrey difundiendo la idea de que su montante no podía exceder de 4.000 ó 5.000 libras, al tiempo que negociaba con los receptores y tesoreros su minoración efectuando cuantos pagos pudieran a partir de estas restas

«En conformidad de la real carta de 20 de março deste presente año que Vuestra Magestad escrivió a los jurados desta Ciudad en mi creencia, les dí noticia de la forma en que Vuestra Magestad fue servido resolver la extinción de la tabla vieja y erección de la nueva, teniendo este expediente por uno de los más importantes para su desempeño y el más urjente para el estado en que se allava. Y repararon para ponerle en execución en el capítulo último de mi carta en que Vuestra Magestad exceptúa del cargamento general el dinero que estubiese en la tabla en nombre de Vuestra Magestad o de sus receptores y thesoreros, mandando que se pasase al libro de la tabla nueva para que Vuestra Magestad

49. ACA. CA .Leg. 678 , doc. $25 / 14$.

50. ACA. CA. Leg. 678 , doc. $25 / 10$. 
se pudiese valer dél sin pérdida alguna. Y haviendo tenido muchas conferencias sobre este artículo, de que quisieron réplica, y io lo escusé haçiendo las instancias possibles con ellos para que pussiessen en execución la extinción en todo y por todo como Vuestra Magestad lo mandava significándoles que el dinero que podría estar en la tabla en nombre de Vuestra Magestad o de sus receptores y thesoreros no podría ser cantidad tan considerable que ynposivilitase a la Ciudad de poderla suplir Vuestra Magestad de quien en éste y los demás expedientes recivía y avía de rrecivir tanta gracia y merced. Y juntamente les ofrecí atender con particular cuidado a que los receptores y thesoreros minorasen sus rentas pagando quanto pudiesen con justificación y no consintiendo que admitiesen partida que se les pagase que no fuese de plaço passado, con el cual, creyendo que estas cantidades no excederían de quatro a cinco mil libras pasaron la extinción por quitamiento y Consejo General y hicieron el pregón publicándola en la mesma forma que se contiene en la real carta que Vuestra Magestad me mandó escrivir...m."

Sin embargo, averiguaciones más precisas permitieron determinar que las restas propiedad del monarca que debían pasar de la Taula vieja a la nueva eran muy superiores a lo que en principio se pudo pensar. Según certificación de Dionisio Noguera, regente del libro mayor de la misma, fechada el 9 de mayo de 1634, estaban conformadas por las siguientes partidas:

- Recepta de la Bailía General
- amortizaciones:
- selio
- expulsión de moriscos
- recepta de Montesa
- donativos y expedientes
- de las 20.000 libras del privilegio de insaculación
- del protonotario Jerónimo Villanueva
- del receptor del Santo Oficio
- de la expulsión de los moriscos otra partida de
- del tesorero
- de restas de visitas de Diputación y Ciudad

\begin{tabular}{|c|c|c|c|c|c|}
\hline 3.771 & libras & 11 & sueldos & 11 & ner \\
\hline 43 & $》$ & 2 & $\gg$ & 2 & $\gg$ \\
\hline 20 & $》$ & 4 & $\gg$ & & \\
\hline 1.284 & 》) & 9 & )) & & \\
\hline 3.415 & $\gg$ & 13 & $\gg$ & & \\
\hline 2.094 & $\gg$ & 8 & 》) & & \\
\hline 1.676 & 》) & 3 & 》) & 5 & » \\
\hline 1.360 & 》) & 9 & $\gg$ & 7 & 》) \\
\hline 58 & $\gg$ & 19 & $\gg$ & 7 & $\gg$ \\
\hline 2.202 & $\gg$ & 29 & $\gg$ & & \\
\hline 1.044 & 》) & 7 & $\gg$ & & \\
\hline 3.900 & $\gg$ & & & & \\
\hline
\end{tabular}

Así, se pudo determinar que la suma de todas ellas ascendía a 31.053 libras, 4 sueldos y 6 dineros. Esta noticia provocó gran preocupación entre los comerciantes, quienes temerosos de que la transferencia de esta cantidad a la nueva taula que se debía abrir se hiciera a partir de sus depósitos dejaron de negociar por el banco municipal, lo que, sin duda, dificultaba enormemente la puesta en marcha de la nueva Taula que, como advertían los jurados al monarca, no podría tener efecto en tanto los hombres de negocios no perdieran todo recelo

«Y havent arribat a notícia dels negociants que una resta tan considerable havia de pasar al llibre nou, se han retirat de fer entrades y de comersiar en la taula nova, recelosos del dany que.ls pot resultar de què dits alcanços se cobren de les pecúnies de què ells faran entrada. Y així no solament ha espirat en sos principis la dita taula nova però vindrà a ser de ningun effecte si Vostra Magestat no mana moderar lo desusdit real orde de forma que los negociants perden tot lo reçel, lo qual fi solament se pot conseguir venent-se los dits crèdits

51. ACA. CA. Leg. 678 , doc. $25 / 9$. 
de dita taula vella, o los que excediran les dites quatre milia lliures que.s dix restarien per compte de Vostra Magestat, les quals se pagaran per dita taula nova, puix ab presupòssit de què no eren més se executà tal extinció. A més de què en cas que per los negociants no.s haguera mogut esta dificultat havia de ser forçós lo succés de la total ruyna de dita taula nova perquè havent-se de pagar una resta tan gran vinguera a consumir-se en ella casi la mitat de tot lo que importava lo peu que Vostra Magestat ha manat donar a la dita taula nova ab la suspensió del despaig dels albarans per temps de sis mesos a que se ajustaria la necessitat del diner en què al present se troba la ciutat per a la provisió y avituallament de les carns. De tot lo qual havem acordat donar rahó y compte a Vostra Magestat a qui supplicam quant humilment podem sia de son real servey apiadar-se de les grans apretures y necessitats que dita ciutat també pateix manant veure y considerar totes les coses desusdites... $>{ }^{52}$

Para obviar este inconveniente el marqués de los Vélez propuso dos posibles soluciones, advirtiendo que cualquiera de ellas sería suficiente para garantizar que, sin que se produjera retraso en la puesta en funcionamiento de la Taula nueva, la Ciudad pudiera acomodar estas partidas y servir al rey. Consistía la primera de ellas en que el Municipio traspasara a la Taula nueva solamente entre 6.000 y 8.000 libras de las partidas más importantes de las restas, debiendo dar orden el monarca a sus receptores de que vendieran el resto al mayor interés posible aunque ello supusiera alguna merma a la hacienda real. De éstas quedarían excluidas, además de las 8.000 libras que pasarían a la Taula nueva, 3.478 libras 8 sueldos y 4 dineros que importaban conjuntamente las dos partidas procedentes de los bienes de los moriscos expulsados, que deberían servir para pagar censales de la aljama; 2.012 libras 11 sueldos y 6 dineros procedentes de las condenas impuestas por el visitador Pueyo, de las que el rey hizo merced a la Ciudad en misiva de 2 de noviembre de 1625, en compensación por las casi 13.000 libras que ésta había empleado en el pago de los salarios y demás gastos derivados de la inspección; y 1.236 libras 11 sueldos y 6 dineros procedentes de las visitas posteriores. De las otras restas, proponía el virrey que el monarca pagara el interés del «daño» de la Taula vieja, reduciendo a moneda efectiva las partidas que quedaran desfalcadas al interés del 14 ó 15\%. Como segunda solución proponía el virrey que todas las partidas de la Taula vieja, salvo las procedentes de la expulsión de los moriscos y de las visitas - sin pasar cantidad alguna a la Taula nueva- se vendieran, repartiéndose el «daño» del interés entre la Ciudad y el rey. ${ }^{53}$

La pérdida del volumen de la contabilidad de la Taula correspondiente a 1635 nos priva, de momento, de conocer cómo se resolvió finalmente esta cuestión. Pero sabemos que el 13 de abril de 1635 los jurados dispusieron que Dionisio Noguera tuviera concluido el libro de la Taula Vella el último día de este mes y anotara el montante de las restas en el libro nuevo. Simultáneamente le nombraron regente del libro mayor de la Taula Vella y de la Taula Vellísima con la misión de pasar las partidas de los libros manuales al libro mayor de la Taula y de «acordar» las cuentas. ${ }^{54}$ Parecía zanjarse así

52. AMV. MC. reg. 161, fol. 591

53. ACA. CA. Leg. 678, doc. 25/9.

54. AMV. MC. reg. 161, fol. 591. 
la grave crisis que en las finanzas municipales había provocado la carestía de trigo en la dificil coyuntura de 1629-1631, pero lo cierto es que la ciudad de Valencia no conseguiría recuperarse totalmente y que en los años siguientes asistiremos a una progresiva agudización de la misma, jalonada por nuevos sobresaltos, como el vivido en el periodo especialmente dramático de 1647-48. 